\title{
Common Bile Duct Stone Formation Induced by Tomato Skin Following Endoscopic Sphincterotomy
}

An 83-year-old female patient with a previous history of cholecystectomy was referred to our Department of Surgery complaining of epigastric pain and obstructive jaundice. Endoscopic retrograde cholangiography (ERC) revealed common bile duct (CBD) stones, which were completely removed after endoscopic sphincterotomy. One year later, the patient was readmitted due to severe abdominal pain in the right subcostal region. ERC showed a normal cholangiogram, a narrowed orifice ( $5 \mathrm{~mm}$ ) of the papilla of Vater, as well as two stones and three foreign bodies $(40 \times 2-3 \mathrm{~mm})$ in the CBD (Figure 1). Extension of the sphincterotomy to $8 \mathrm{~mm}$ was performed, and the foreign bodies were extracted together with the stones (Figure 2). The macroscopic and microscopic examination of the foreign bodies proved that they were tomato skins. The patient reported that she had been regularly consuming tomatoes.

Since the first application of endoscopic sphincterotomy in 1973 (1, 2 ) it has become an established treatment modality for biliary tract diseases such as CBD stones. Following cholecystectomy, formation of common bile duct stones can occur due to various factors, such as the presence of bile duct anastomoses, ampullary stenosis, and lithogenesis of the bile (3), but they can also be induced by surgical material, especially in conjunction with cholestasis and consequent bile infection. Similarly, stone formation can follow other interventions, such as EST or iatrogenic choledochoduodenal fistulas. Foreign bodies can enter the $\mathrm{CBD}$ via a wide sphincterotomy, as probably happened in our case, or through the fistulas of the extrahepatic bile ducts, to induce stone formation (4). We speculate that the symptoms in our case coincided with restenosis of the papilla leading to impaired bile flow.

I. Szántól ', E.M. Gamal ${ }^{\prime}$, J. Banai ', A. Bajtai ${ }^{2}$,

I. Bozalyi ${ }^{3}$, I. Dobó $^{1}$

${ }^{1}$ Department of Surgery, ${ }^{2}$ Institute of Pathology, and ${ }^{3}$ Department of Radiology, Postgraduate Medical School, Budapest, Hungary

\section{References}

1. Classen M, Demling L: Endoskopische Sphinkterotomie der Papilla Vateri und Steinextraktion aus dem Ductus Choledochus. Dtsch Med Wschr 1974; 20: 496-497.

2. Kawai $K$, Akasaka Y, Murakami $K$ et al.: Endoscopic sphincterotomy of the ampulla of Vater. Gastrointest Endosc 1974; 20: $148-151$.

3. Silvennoinen $E$ : Concrements resulting from suture material in the biliary tract: a clinical and experimental study. Ann Chir Gynaecol Fenn Suppl 1970: 59.

4. Kun M, Szántó I, Dobó I et al.: Iatrogenic parapapillary choledochoduodenal fistulas. Acta Endosc 1987; 17: 195-200.

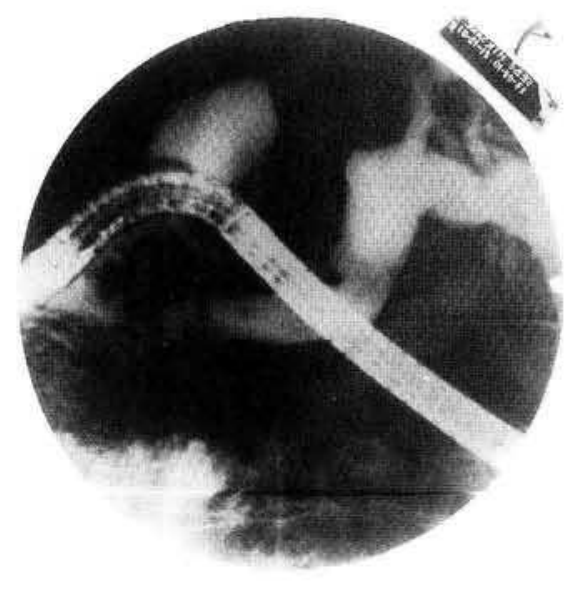

Figure 1:

ERC showing

foreign bodies of different lengths in the CBD. The stones, which were also extracted after EST, are behind the endoscope.

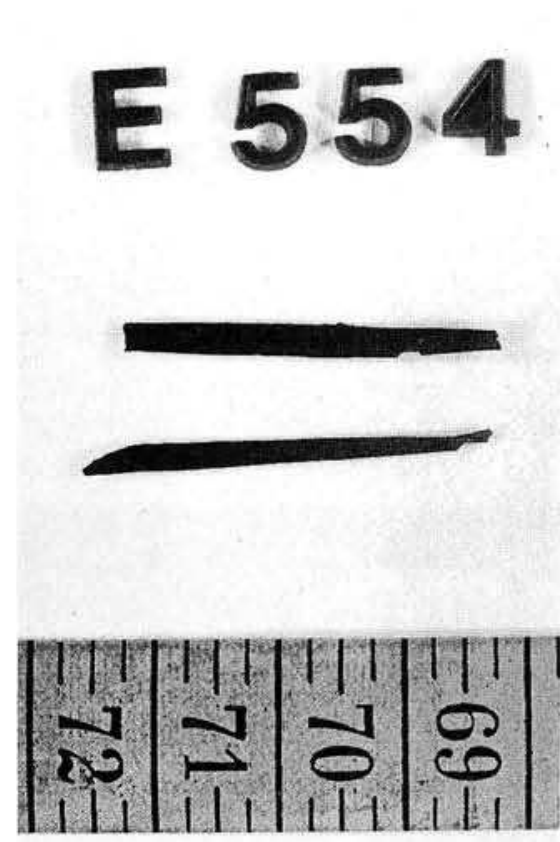

Figure 2:

The extracted foreign bodies.

\section{Corresponding Author}

L. Szántó, M.D., Department of Surgery, Postgraduate Medical School, Szabolcs 35, P.O. Box 112, 1389 Budapest, Hungary 